\title{
$\mu$-Opioid Receptor-Mediated Depression of the Hypothalamic Hypocretin/Orexin Arousal System
}

\author{
Ying Li and Anthony N. van den Pol \\ Department of Neurosurgery, Yale University School of Medicine, New Haven, Connecticut 06520
}

\begin{abstract}
Arousal and maintenance of a wake state is dependent on the hypothalamic hypocretin/orexin system. We found that hypocretin neurons are depressed by opiates, drugs of abuse that reduce cognitive alertness. Met-enkephalin (mENK), an endogenous opioid, and exogenous opiates such as morphine inhibited the hypocretin system by direct actions on the cell body that include reduced spike frequency, hyperpolarization, increased G-protein-coupled inwardly rectifying $\mathrm{K}^{+}$channel current, and attenuated calcium current, and indirectly through reducing excitatory synaptic tone by a presynaptic mechanism. CTAP (H-D-Phe-Cys-Tyr-D-Trp-Arg-Thr-Pen-Thr- $\mathrm{NH}_{2}$ ) and naloxone, antagonists of $\mu$-opioid receptors, blocked $\mu$ agonist actions. In the absence of exogenous opioids, $\mu$ receptor antagonists enhanced activity of the hypocretin system, suggesting ongoing inhibition by endogenous receptors. Morphine pretreatment attenuated subsequent excitatory responses to hypocretin, suggesting a long-lasting depression caused by opiate exposure. Chronic exposure to morphine reduced subsequent responses to morphine and to $\mathrm{mENK}$, but increased the response to opioid receptor antagonists. Together, these data are consistent with the view that the hypocretin system may be an important direct target for drugs of abuse, including opiates, that induce sedation and mental lethargy.
\end{abstract}

Key words: hypocretin; orexin; opiate; lateral hypothalamus; addiction; drug abuse

\section{Introduction}

The hypothalamic hypocretin/orexin system plays an important role in maintaining cognitive arousal and attention; loss of the hypocretin system leads to narcolepsy (Peyron et al., 2000; Thannickal et al., 2000). Hypocretin axons project to a number of brain regions that are thought to play a role in the addictive actions of drugs of abuse, including the ventral tegmental area, locus ceruleus, nucleus accumbens, and lateral hypothalamus (LH) (Nestler and Aghajanian, 1997; Peyron et al., 1998). The opiate morphine increases cAMP response element (CRE) expression in hypocretin neurons, but not in nearby melaninconcentrating hormone $(\mathrm{MCH})$ neurons. Morphine cessation increases hypocretin mRNA (Zhou et al., 2006) and induces c-fos in hypocretin cells, and withdrawal symptoms are attenuated in hypocretin-knock-out mice (Georgescu et al., 2003). Hypocretin neurons are activated by cues associated with drug and food reward (Harris et al., 2005). Together, these data suggest that the hypocretin cells may respond to morphine and that hypocretin cells may be part of the neural network involved in responses to some addicting substances.

The addictive nature of drugs has been linked to what have been called reward centers of the brain, regions where rodents and humans will electrically self-stimulate implanted electrodes.

Received Dec. 10, 2007; revised Jan. 24, 2008; accepted Feb. 1, 2008.

This work was supported by National Institutes of Health Grants NS48476, NS41454, and NS34887. We thank Dr. George Aghajanian for facilitation, help, and valuable suggestions for some of the opiate experiments, Dr. Ralph DiLeone for suggestions on this manuscript, and Y. Yang and V. Rogulin for technical assistance.

Correspondence should be addressed to Anthony N. van den Pol, Department of Neurosurgery, Yale University School of Medicine, 333 Cedar Street, New Haven, CT 06520. E-mail: anthony.vandenpol@yale.edu.

DOI:10.1523/JNEUROSCI.5447-07.2008

Copyright $\odot 2008$ Society for Neuroscience $\quad 0270-6474 / 08 / 282814-06 \$ 15.00 / 0$
The LH, in which hypocretin neurons occur, supports one of the highest rates of electrical self-stimulation found in the brain (Wise, 2002). LH neurons may play a role in the hedonic nature of self-stimulation (Lestang et al., 1985; Nassif et al., 1985).

The LH contains $\mu$-opioid receptors (Mansour et al., 1988; Desjardins et al., 1990), and hypocretin cells express $\mu$-opioid receptor immunoreactivity (Georgescu et al., 2003). Mice will self-administer morphine directly into the LH (Cazala et al., 1987). Activation of hypocretin neurons or application of hypocretin to receptors in the ventral tegmental area reinstates opiate seeking (Harris et al., 2005), and the place preference and hyperlocomotion associated with morphine are attenuated in mice lacking hypocretin (Narita et al., 2006). Although these studies show that opiates influence the hypocretin system, whether this effect is direct or indirect has not been tested. Many drugs of abuse, particularly opiates such as morphine and heroin, tend to produce a lethargic state in drug users. We asked whether opiates might directly depress neurons of the hypocretin arousal system; a depressed arousal system might lead to reduced cognitive arousal. We used whole-cell recording in hypothalamic brain slices to study both direct and indirect responses of identified hypocretin cells to endogenous opioids and exogenous opiates in acute experiments and after continuous exposure.

\section{Materials and Methods}

To study the responses of identified hypocretin neurons to opioids, whole-cell recording was used in LH brain slices. Hypocretin-GFP transgenic mice (from Dr. T. Sakurai, Tsukuba University, Ibaraki, Japan) were used that expressed green fluorescent protein (GFP) selectively in hypocretin cells (Li et al., 2002). Use of animals was approved by the Yale University Committee on Animal Care and Use. Mice 14-28 d of age 
A.

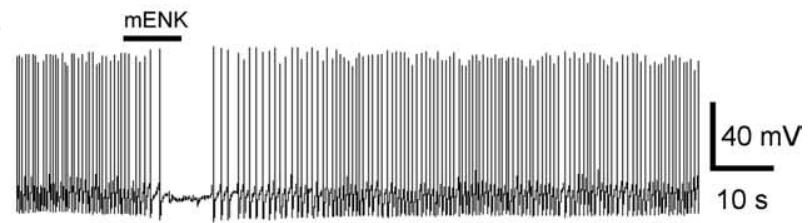

B.

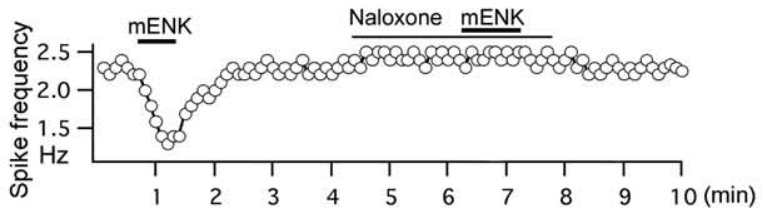

C.

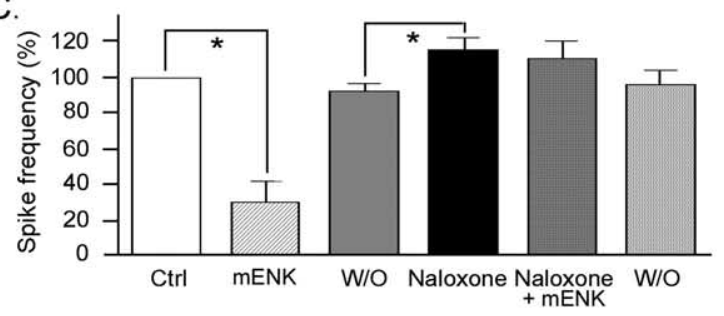

D.

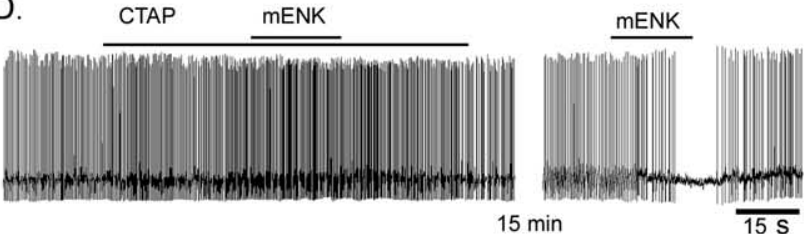

E. sEPSC

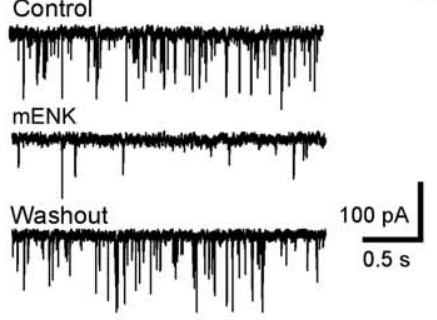

G
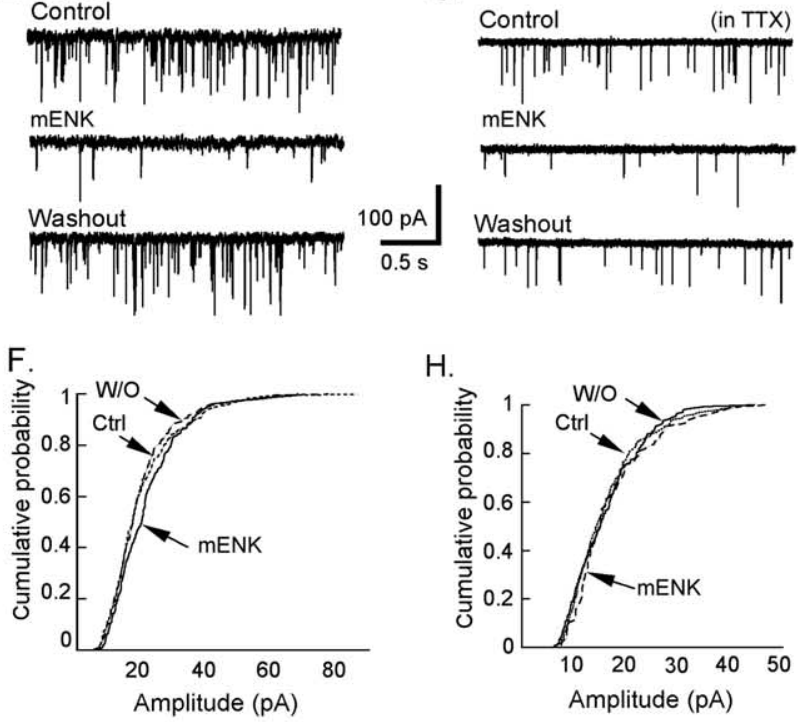

H.
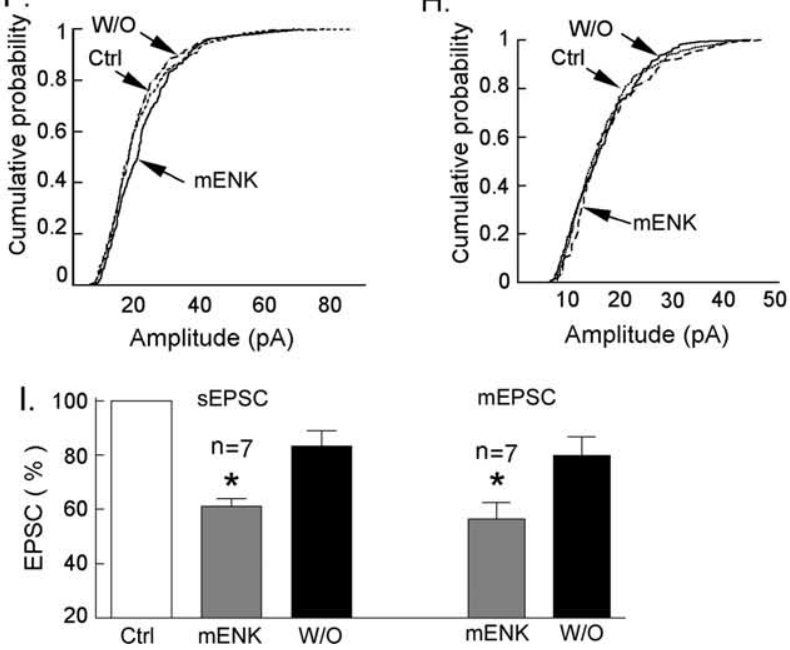

Figure 1. mENK inhibits hypocretin neurons. $A$, A typical cell showing that $m E N K(100 \mu \mathrm{M})$ blocked spikes under current clamp. $\boldsymbol{B}$, Naloxone $(10 \mu \mathrm{m})$ blocked mENK-induced inhibition. $\boldsymbol{C}$, A bar graph showing that naloxone $(10 \mu \mathrm{m})$ increased spike frequency $(n=6 ; p<0.05)$. $\boldsymbol{D}$, Specific $\mu$-opiate receptor antagonist CTAP blocks mENK-induced decrease in spike frequency. $\boldsymbol{E}$, An example cell showing the effect of mENK on sEPSC frequency. $\boldsymbol{F}$, A typical cell showing that mENK $(100 \mu \mathrm{m})$ did not change sEPSC amplitude. $\mathbf{G}$, mENK (100 $\mu \mathrm{m})$ decreased mEPSC were anesthetized with Nembutal $(100 \mathrm{mg} / \mathrm{kg})$ and decapitated, and the brains were removed. LH coronal slices (250-300 $\mu \mathrm{m}$ thick) were cut and constantly bubbled with $5 \% \mathrm{CO}_{2}$ and $95 \% \mathrm{O}_{2}$.

Whole-cell patch recordings were made with an EPC9 amplifier and Pulse 8.5 software (Heka, Lambrecht, Germany), as described previously in detail (Li et al., 2002). GFP-expressing hypocretin neurons were visualized using a differential interference contrast optical system combined with an infrared filter, a GFP fluorescent filter, and monochrome CCD camera. Recording pipettes had resistances between 4 and $6 \mathrm{M} \Omega$ when filled with recording solution (in mM: $145 \mathrm{KMeSO}_{4}, 1 \mathrm{MgCl}_{2} ; 10 \mathrm{HEPES}$; 1.1 EGTA, $2 \mathrm{Mg}$-ATP, and $0.5 \mathrm{Na}_{2}$-GTP, adjusted to $\mathrm{pH} 7.3$ with $\mathrm{KOH}$ ). To study calcium currents, the bath solution contained the following: 100 mм NaCl, 40 mм TEA-Cl, 2.5 mm KCl, 5 mm BaCl, 10 mм HEPES, 10 mM glucose, and $1 \mu \mathrm{M}$ TTX; $\mathrm{pH}$ was adjusted to 7.3 with $\mathrm{KOH}$. The pipette solution contained (in $\mathrm{mm}$ ): $135 \mathrm{CsCl}, 1 \mathrm{MgCl}_{2}, 10 \mathrm{HEPES}, 5$ BAPTA-Cs, $4 \mathrm{Mg}$-ATP, and $0.5 \mathrm{Na}_{2}$-GTP; pH was adjusted to 7.3 with $\mathrm{CsOH}$. Any neuron in which the series resistance was $>20 \mathrm{M} \Omega$ and changed by $>15 \%$ during the experiment was judged unstable, and was therefore discarded from further analysis. Pulsefit 8.5, Axograph 4.8, and IgorPro Carbon 4.07 (WaveMetrics, Lake Oswego, OR) software were used to analyze and plot data.

A holding potential of $-60 \mathrm{mV}$ was used to record EPSCs in the presence of bicuculline $(30 \mu \mathrm{M})$. Bicuculline $(30 \mu \mathrm{M})$ and TTX $(0.5 \mu \mathrm{M})$ were added to the bath to record miniature EPSCs. To analyze synaptic activity, only events with amplitudes $>5 \mathrm{pA}$ were used (Gao and van den Pol, 1999). The Kolmogorov-Smirnoff statistical test was used to measure cumulative probability of synaptic events. Except where otherwise noted, a one-way ANOVA was used for statistical tests. Data are presented as mean $\pm \mathrm{SE}$, and statistical significance was determined with a criterion of $p<0.05$.

In one experiment, mice were subcutaneously implanted with a pellet of morphine (37.5 mg) (Lane-Ladd et al., 1997), and recordings were conducted $65 \mathrm{~h}$ later. Another group of mice were subcutaneously implanted with the same weight of placebo vehicle as a sham control. Brain slices were then prepared, and responses to $\mu$ receptor agonists and antagonists were studied.

Drugs were applied by large-diameter ( $400 \mu \mathrm{m}$ tip) flow pipette in front of a multi-input manifold. When drugs were not applied, extracellular buffer was applied. TTX was obtained from Alomone Labs (Jerusalem, Israel) and hypocretin from the Stanford University Peptide Facility. DL-2-Amino-5-phosphonovaleric acid (AP5), 6-cyano7-nitroquinoxaline-2,3-dione (CNQX), bicuculline methiodide (BIC), [Met5] enkephalin (mENK), dynorphin A porcine fragment 1-13, [D-Ala $\left.{ }^{2}, \mathrm{D}-\mathrm{Leu}^{5}\right]$-enkephalin (DADLE), morphine, naloxone, H-D-Phe-Cys-Tyr-D-Trp-Arg-Thr-Pen-Thr- $\mathrm{NH}_{2}$ (CTAP), and [D-Ala ${ }^{2}-\mathrm{N}-\mathrm{Me}^{-P h e} \mathrm{e}^{4}-\mathrm{Gly}^{5}$-ol]-enkephalin (DAMGO) were from Sigma-Aldrich (St. Louis, MO). Morphine pellets were obtained from the National Institute on Drug Abuse.

\section{Results}

Met-enkephalin and morphine inhibit hypocretin neurons $\mathrm{mENK}$ is an endogenous opioid peptide synthesized by hypothalamic neurons (Fallon and Leslie, 1986); the $\mathrm{mENK} \mu$ receptor is also expressed in the lateral hypothalamus (Mansour et al., 1988), including cells that synthesize hypocretin (Georgescu et al., 2003). mENK (100 $\mu \mathrm{M})$ inhibited the spike frequency of hypocretin neurons, reducing spikes from $3.2 \pm 0.5$ to $0.3 \pm 1 \mathrm{~Hz}$ (range from 0 to $0.7 \mathrm{~Hz} ; n=7$ ), an $87 \pm 5.4 \%$ reduction $(p<$ 0.05 ) (Fig. 1A); mENK reduced spike frequency in each of the seven cells tested. Spike frequency then returned to $2.5 \pm 0.3 \mathrm{~Hz}$ after mENK washout. mENK hyperpolarized the membrane potential by $4 \mathrm{mV}$, from $-62 \pm 0.5$ to $-66 \pm 0.8 \mathrm{mV}(n=7 ; p<$

frequency. $\boldsymbol{H}$, A typical cell showing that mENK (100 $\mu \mathrm{M})$ did not change mEPSC amplitude. $\boldsymbol{I}$, Bar graph showing that $\mathrm{mENK}(100 \mu \mathrm{M})$ decreased spontaneous $(n=7)$ and miniature $(n=7)$ EPSC frequency $(p<0.05)$. W/0, Washout. ${ }^{*} p<0.05$. 
A. Morphine decreases spike frequency

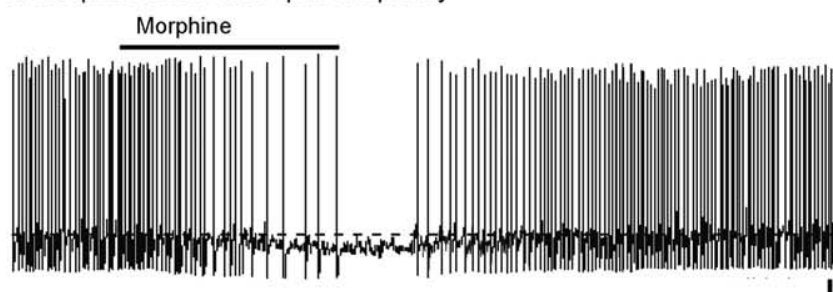

$\frac{30 \mathrm{mV}}{10 \mathrm{~s}}$

B. Morphine hyperpolarizes the membrane potential

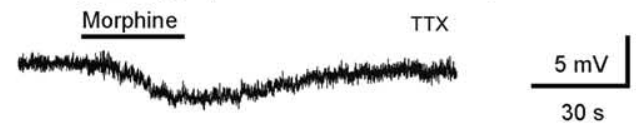

C. Morphine inhibits $\mathrm{Ca}^{2+}$ current

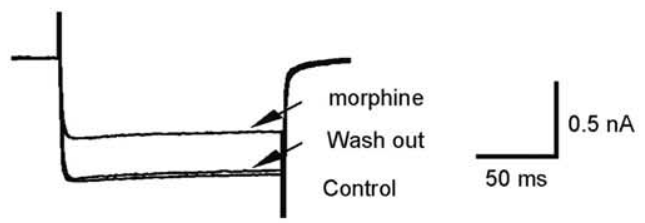

D. mENK hyperpolarizes the membrane potential

mENK

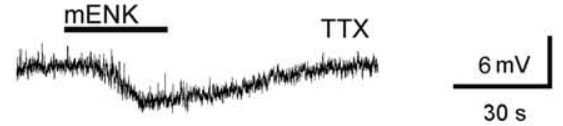

E1. mENK induces GIRK current
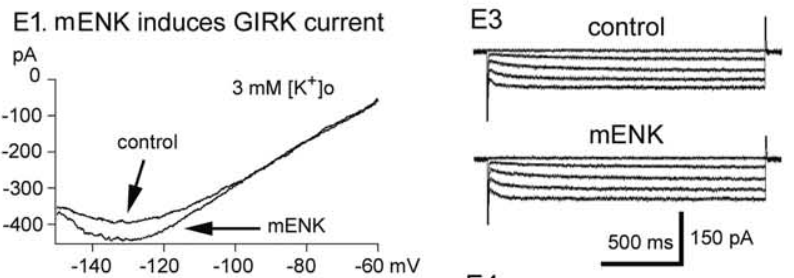

E2
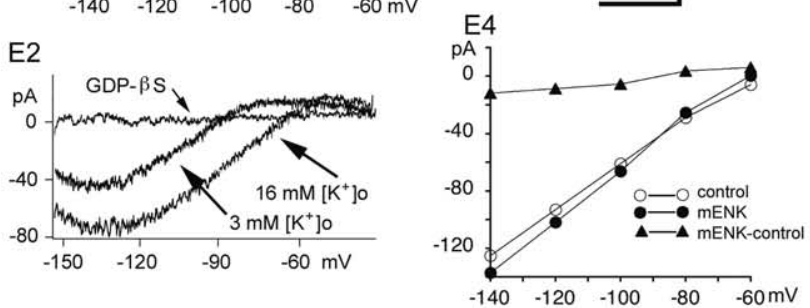

F. Morphine decreases mEPSC frequency

Control

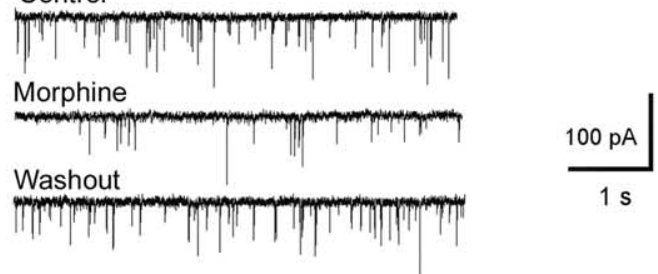

Figure 2. Morphine inhibits hypocretin neurons. $\boldsymbol{A}$, Morphine $(10 \mu \mathrm{M})$ reduced spike frequency and hyperpolarized the membrane potential. $\boldsymbol{B}$, Morphine $(10 \mu \mathrm{m})$ hyperpolarized the membrane potential in TTX $(0.5 \mu \mathrm{m}), \operatorname{AP5}(50 \mu \mathrm{M}), \mathrm{CNQX}(10 \mu \mathrm{m})$, and BIC (30 $\mu \mathrm{M})$. C, Morphine $(10 \mu \mathrm{M})$ inhibited the $\mathrm{Ba}^{2+}\left(\mathrm{Ca}^{2+}\right)$ current evoked by a step depolarization. $\boldsymbol{D}$, mENK (50 $\mu \mathrm{M})$ hyperpolarized the membrane potential in TTX $(0.5 \mu \mathrm{M}), \operatorname{AP5}(50 \mu \mathrm{M}), \mathrm{CNQX}(10 \mu \mathrm{m})$, and BIC $(30 \mu \mathrm{M}) . \boldsymbol{E}$, mENK-mediated current is $\mathrm{G}$-protein-coupled inwardly rectifying potassium current. $\boldsymbol{E 1}$, Control and $\mathrm{mENK}$-induced inward current generated by a ramp pulse from -160 to $+10 \mathrm{mV}$ under voltage clamp. The cells were in TTX $(0.5 \mu \mathrm{M}), \mathrm{AP5}(50 \mu \mathrm{M}), \mathrm{CNQX}(10 \mu \mathrm{M})$, and bicuculline $(30 \mu \mathrm{m})$. Holding potential $=-90 \mathrm{mV}$. E2, The resultant currents after subtraction of the control from mENK current. mENK-mediated current is potassium and GTP dependent. E3, Current responses to $20 \mathrm{mV}$ voltage steps from -140 to $-60 \mathrm{mV}$ in the presence or absence of $\mathrm{mENK}$. $\boldsymbol{E} 4$, The reversal potential of $\mathrm{mENK}$-induced current was near $E_{\mathrm{K}} . \boldsymbol{F}$, Morphine $(10 \mu \mathrm{m})$ reduced $\mathrm{mEPSC}$ frequency.
$0.05)$, then returned to $-63 \pm 0.6 \mathrm{mV}$ after washout. The opioid receptor antagonist, naloxone $(10 \mu \mathrm{M})$, blocked the mENKinduced inhibition $(n=4)$ (Fig. $1 B)$.

$\mu$ receptor antagonists increase activity of hypocretin neurons

Interestingly, naloxone alone, in the absence of exogenous $\mathrm{mENK}$, increased spike frequency by $26 \pm 6 \%(n=6 ; p<0.05)$ (Fig. $1 B, C$ ) under current clamp, a statistically significant rise. Although naloxone does block the mENK inhibitory action, it is not selective for the $\mu$ receptor. We therefore also used the $\mu$ receptor-selective antagonist CTAP. CTAP $(10 \mu \mathrm{M})$ blocked the $\operatorname{mENK}(100 \mu \mathrm{M})$-mediated depression of spike frequency (98 \pm $5 \%$ of control). After CTAP and mENK were washed out for 15-20 min, application of $\mathrm{mENK}$ alone did inhibit spike frequency by $87 \pm 11 \%(n=5 ; p<0.05)$ (Fig. $1 D)$. To address the question of whether endogenous $\mu$-opioids might be spontaneously released, we used CTAP in the absence of the $\mu$ agonist. In current clamp, CTAP by itself increased spike frequency by $27.8 \pm 7.7 \%$, a statistically significant increase $(n=8 ; p<0.05)$. Together, these data suggest that hypocretin cells may be under ongoing inhibitory repression by active $\mu$ receptors.

Opioids reduce excitatory input to hypocretin cells by presynaptic mechanism

mENK decreased the frequency of spontaneous EPSCs by $61 \pm$ $3 \%(n=7 ; p<0.05)$ (Fig. $1 E, I)$, and then the frequency recovered to $83 \pm 6 \%$ after peptide washout. To determine whether the actions might be presynaptic, miniature EPSCs (mEPSCs) were studied in the presence of TTX $(0.5 \mu \mathrm{M})$. mENK $(100 \mu \mathrm{M})$ decreased the frequency of mEPSCs by $56 \pm 6 \%(n=7 ; p<0.05)$ (Fig. $1 G, I$ ), and the frequency returned to $79 \pm 7 \%$ after washout. mENK $(100 \mu \mathrm{M})$ did not change the amplitude of spontaneous EPSCs (sEPSCs) or mEPSCs (Kolmogorov-Smirnoff test, $p>$ 0.05 ) (Fig. $1 F, H$ ). These results are consistent with a presynaptic site of action of mENK in attenuating the frequency but not amplitude of mEPSCs.

To determine whether mENK influences calcium currents, the holding potential of recorded neurons was set at $-80 \mathrm{mV}$, and then a step pulse was applied from -80 to $0 \mathrm{mV}$ for $100 \mathrm{~ms}$ before, during, and after application of mENK. $\mathrm{Ba}^{2+}$ was used as the charge carrier in place of $\mathrm{Ca}^{2+} . \operatorname{mENK}(100 \mu \mathrm{M})$ decreased $\mathrm{Ba}^{2+}$ currents by $56 \pm 3.9 \%(n=6 ; p<0.05)$.

$\boldsymbol{\mu}$ agonists depress hypocretin neurons by activating Gprotein-gated inwardly rectifying $\mathrm{K}^{+}$channel, depressing calcium currents, and reducing synaptic glutamate release The $\mu$ receptor opiate agonist morphine $(10 \mu \mathrm{M})$ reduced spike frequency from $3.0 \pm 0.2$ to $0.5 \pm 0.2 \mathrm{~Hz}(15.6 \pm 6.3 \% ; n=7$; ANOVA test, $p<0.05$ ) (Fig. $2 A$ ), and spike frequency recovered to $2.6 \pm 0.3 \mathrm{~Hz}$ after washout; all cells tested with morphine showed a spike decrease. Morphine $(10 \mu \mathrm{M})$ hyperpolarized the membrane potential from $-60 \pm 1.4$ to $-66 \pm 1.5 \mathrm{mV}$ (ANOVA test, $p<0.05$ ), which recovered to $-61 \pm 1.1 \mathrm{mV}$ after washout. Morphine $(1 \mu \mathrm{M})$ decreased spike frequency from $3.9 \pm 0.4$ to $2.2 \pm 0.5 \mathrm{~Hz}(n=5 ; p<0.05)$, which then returned to $3.3 \pm 0.3$ $\mathrm{Hz}$ after washout. Morphine $(1 \mu \mathrm{M})$ hyperpolarized the membrane potential from $-58 \pm 0.8$ to $-62 \pm 1.2 \mathrm{mV}(n=5 ; p<$ 0.05 ), then returned to $-59 \pm 0.9 \mathrm{mV}$ after washout. Figure $2 \mathrm{~A}$ shows a representative trace in which morphine reduced the spike frequency and hyperpolarized the membrane potential.

In the presence of TTX $(0.5 \mu \mathrm{M})$, morphine $(10 \mu \mathrm{M})$ hyperpolarized the membrane potential by $4.2 \pm 0.8 \mathrm{mV}(n=7$; 
ANOVA) (Fig. 2B). As shown in Figure 2C, morphine $(10 \mu \mathrm{M})$ also decreased $\mathrm{Ca}^{2+}$ current by $44 \pm 4.8 \%(n=6 ; p<0.05)$. $\operatorname{mENK}(50 \mu \mathrm{M})$ hyperpolarized the membrane potential by $6 \pm$ $1.3 \mathrm{mV}$ in the presence of TTX $(n=8$; ANOVA) (Fig. $2 D)$. To examine whether the $\mu$ receptor agonist would induce an inwardrectified potassium current, a ramp pulse from $-160 \mathrm{mV}$ to +10 $\mathrm{mV}$ was applied to hypocretin neurons under voltage clamp. The ramp pulse was applied at $5 \mathrm{~s}$ intervals for durations of $200 \mathrm{~ms}$. When the current in the presence of $\mathrm{mENK}$ was subtracted from the control current, a mENK-mediated current was found that showed inward rectification (Fig. $2 E 1, E 2)(n=10)$. When extracellular potassium concentration was increased from 3 to $16 \mathrm{~mm}$, the reversal potential shifted from $-90 \mathrm{mV}$ to $-60 \mathrm{mV}$, suggesting that the mENK-mediated current was potassium dependent (Fig. 2E2) $(n=6)$. When the nonhydrolyzable GDP analog GDP- $\beta S(800 \mu \mathrm{M})$ was used in the recording pipette and the cell was held in voltage clamp, $\operatorname{mENK}(50 \mu \mathrm{M})$ induced a current. However, after washout for $5 \mathrm{~min}$, the second application of mENK did not induce a current (Fig. 2 E2) $(n=6)$. This suggests that the mENK-mediated current was GTP dependent. Responses to $\mathrm{mENK}(50 \mu \mathrm{M})$ were also studied with voltage steps (Fig. 2 E3,E4) $(n=8)$. Step pulses were given from $-140 \mathrm{mV}$ to $-60 \mathrm{mV}$ with $20 \mathrm{mV}$ increments. The reversal potential of the mENK-induced current was approximately $-90 \mathrm{mV}$.

Similar to mENK, morphine $(10 \mu \mathrm{M})$ decreased the frequency of mEPSCs from $4.3 \pm 1.2 \mathrm{~Hz}$ by $40 \pm 9.6 \%(n=7$; ANOVA, $p<$ 0.05 ) (Fig. $2 F$ ), and this recovered to $76 \pm 9.7 \%$ after washout. There was no significant change in the cumulative probability distribution of mEPSC amplitude when control and morphine conditions were compared (Kolmogorov-Smirnoff test, $p>$ 0.05, data not shown), suggesting a presynaptic mechanism. mEPSCs were blocked with glutamate receptor antagonists AP5 $(50 \mu \mathrm{M})$ and CNQX $(10 \mu \mathrm{M})$.

We previously showed that hypocretin cells were directly inhibited by the opioid peptide dynorphin acting at a $\kappa$ receptor $(\mathrm{Li}$ and van den Pol, 2006). We also tested a $\delta$-opioid receptor agonist, DADLE. DADLE $(10 \mu \mathrm{M})$ had little effect on spike frequency (control, $3.0 \pm 0.4 \mathrm{~Hz}$; in DADLE, $2.7 \pm 0.5 \mathrm{~Hz}$; recovery, $2.9 \pm$ $0.4 \mathrm{~Hz}$; nonsignificant difference; $n=6 ; p>0.05)$. In contrast, the $\mu$ agonist DAMGO $(10 \mu \mathrm{M})$ reduced spike frequency from $2.3 \pm 0.5 \mathrm{~Hz}$ to $65 \pm 13 \%$, and hyperpolarized the membrane by $2.2 \pm 0.7 \mathrm{mV}(p<0.05 ; n=9)$. The modest DAMGO depression may be caused by $\mu$ receptor splice variants that have a high affinity for $\mu$ antagonists, but a relatively low affinity for DAMGO (Pan et al., 2005).

\section{Morphine exposure attenuates the subsequent excitatory response to hypocretin}

To determine whether morphine exposure might alter the subsequent response to hypocretin, we used a morphine pretreatment. The slice was pretreated with morphine $(10 \mu \mathrm{M})$ for $1 \mathrm{~h}$, and then the slice was washed with buffer for at least $30 \mathrm{~min}$, during which the spike frequency recovered to premorphine levels. After morphine pretreatment and the prolonged recovery period, Hcrt-1 plus Hcrt-2 (added together) increased spike frequency from $2.0 \pm 0.6 \mathrm{~Hz}$ to $147 \pm 12 \%(n=7 ; p<0.05)$. In contrast, in experiments in which normal buffer was substituted for morphine during the same preexposure period, Hcrt-1 plus Hcrt-2 (1 $+1 \mu \mathrm{M})$ subsequently increased spike frequency from $2.3 \pm 0.7$ Hz to $192 \pm 22 \%(n=7 ; p<0.05)$ (Fig. $3 A)$ of the prehypocretin control levels (defined as $100 \%$ ). Thus, morphine pretreatment caused a long-lasting statistically significant $(p<0.05)$ reduction in the response to hypocretin (Fig. $3 A$ ). In previous work with
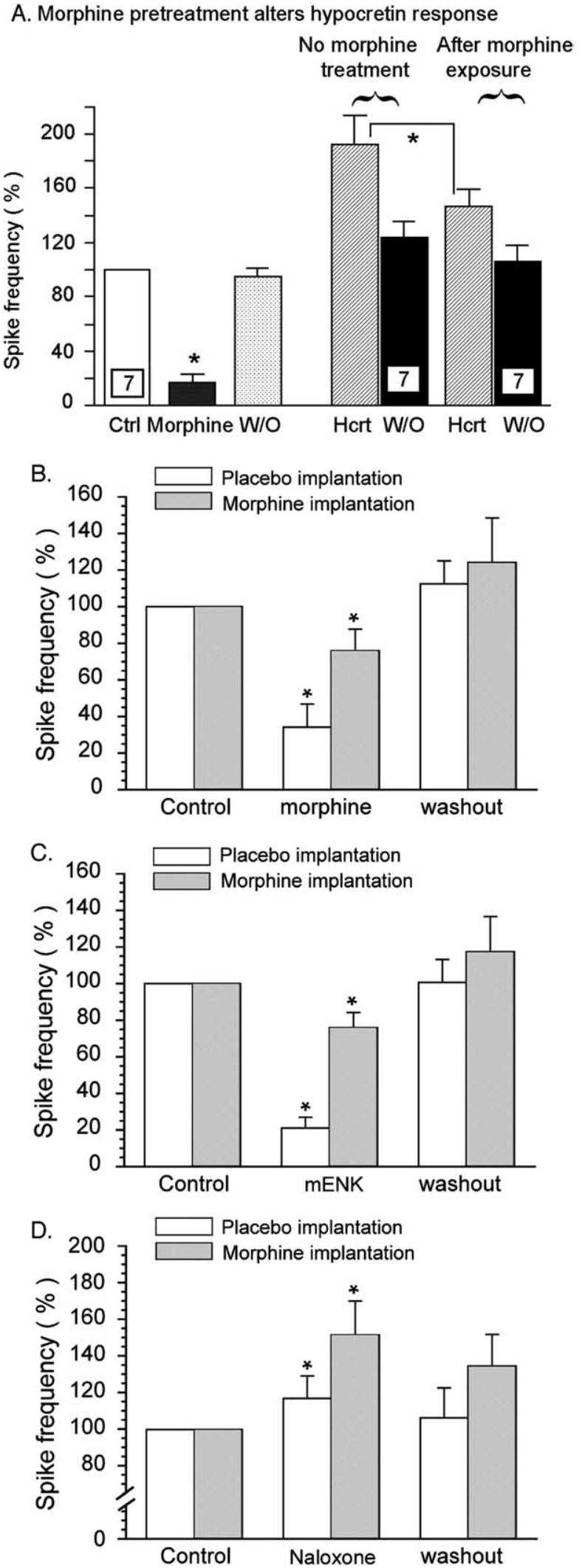

Figure 3. Chronic morphine exposure alters the response to hypocretin, opiate agonist, and antagonist. $\boldsymbol{A}$, Morphine preexposure attenuates the hypocretin-mediated spike increase in hypocretin neurons $(n=7 ; p<0.05)$. W/0, Washout. $\boldsymbol{B}$, The morphine $(10 \mu \mathrm{m})$-induced reduction in spike frequency is reduced by chronic morphine exposure. $\boldsymbol{C}$, The group exposed to chronic morphine also shows an attenuated response to mENK (100 $\mu \mathrm{m})$ compared with controls. $\boldsymbol{D}$, The response of the morphine-exposed group to naloxone (10 $\mu \mathrm{m})$ was greater than the response of the placebo group. ${ }^{*} p<0.05$. 
repeated application of hypocretin under similar temporal paradigms (Li et al., 2002), as well as in the present work, the amplitude of the hypocretin response was unchanged, suggesting that the effects here are not caused by rundown or desensitization.

\section{Chronic exposure to morphine alters responses to morphine}

Recordings were done in slices from mice chronically implanted with morphine. Morphine $(10 \mu \mathrm{M})$ reduced the spike frequency of hypocretin neurons from $2.1 \pm 0.3 \mathrm{~Hz}$ to $75 \pm 12 \%$ of the control in the morphine-implanted group $(n=6$; ANOVA, $p<$ $0.05)$. However, in the placebo-implanted group, morphine had a greater effect, and reduced spike frequency to $34 \pm 14 \%$ of the control $(2.3 \pm 0.5 \mathrm{~Hz})$, a significant difference $(n=6$; ANOVA, $p<0.05)$ (Fig. $3 B)$. mENK $(100 \mu \mathrm{M})$ reduced the spike frequency from $2.2 \pm 0.4 \mathrm{~Hz}$ to $21 \pm 7 \%$ of the control in the placeboimplanted group $(n=6$; ANOVA, $p<0.05)$. Spike frequency was only reduced to $73 \pm 9 \%$ of the control by mENK in morphineimplanted group $(n=6$; ANOVA, $p<0.05)$ (Fig. $3 C)$.

In contrast, the opiate antagonist naloxone $(10 \mu \mathrm{M})$ increased spike frequency from $2.0 \pm 0.5 \mathrm{~Hz}$ by $51 \pm 17 \%$ in the morphineimplanted group $(n=6$; ANOVA, $p<0.05)$, but increased spike frequency from $2.3 \pm 0.3 \mathrm{~Hz}$ by only $16 \pm 14 \%$ in the placeboimplanted control group, a significant difference $(n=6$; ANOVA, $p<0.05$ ) (Fig. $3 D$ ). These data suggest that chronic exposure to morphine reduces the subsequent sensitivity to morphine, but increases the response to morphine antagonists, possibly mediated by changes in second messenger pathways caused by long-lasting receptor activation (Nestler and Aghajanian, 1997).

\section{Discussion}

In the present study, we found that mENK and morphine had direct inhibitory actions on hypocretin neurons, resulting in hyperpolarization, reduced spike frequency, attenuated calcium current, and enhanced potassium current. Hypocretin neurons may be under tonic inhibition by endogenous $\mu$-opioid receptor agonists, because blocking $\mu$ receptors resulted in an increase in spike frequency. Chronic exposure to morphine caused a reduced response to $\mu$ receptor agonists, and an increased response to the opioid receptor antagonist naloxone.

\section{Opiates depress hypocretin neurons}

Treatment with morphine increased CRE reporter expression in hypocretin neurons, but not in nearby $\mathrm{MCH}$ neurons, and withdrawal from morphine increased c-fos in hypocretin cells (Georgescu et al., 2003). The present study demonstrates that hypocretin cells respond directly to morphine and to the endogenous $\mu$ receptor agonist mENK. Both morphine and mENK consistently depressed the activity of hypocretin cells by multiple mechanisms, even when spike-mediated synaptic activity was blocked, indicating a direct effect on receptors of the somatodendritic region of hypocretin cells. Previous work showed that hypocretin knock-out mice showed attenuated withdrawal symptoms after cessation of chronic morphine (Georgescu et al., 2003), suggesting the hypocretin cells may play a role in the response of the CNS to addictive drugs. Morphine also reduced the frequency of mEPSCs with no change in amplitude, suggesting presynaptic inhibition of excitatory axonal input. Pretreatment with morphine attenuated subsequent hypocretin-mediated excitation, revealing a persistent effect of morphine. Because hypocretin excites hypocretin neurons mainly by presynaptic facilitation of excitatory input (Li et al., 2002), this lasting effect of morphine may be caused by a long-lasting or latent attenuation of either glutamate release or postsynaptic glutamate response.

In previous work, chronic morphine induced an increase in CRE in $\sim 25 \%$ of the hypocretin cells, and morphine withdrawal induced c-fos in $\sim 15 \%$ of the cells (Georgescu et al., 2003), leading to the suggestion that only a minority of hypocretin neurons express functional $\mu$ receptors and respond to morphine. In contrast to the CRE and c-fos response in a subset of cells, in the present electrophysiological study, virtually all hypocretin neurons tested with morphine or the $\mu$ agonist mENK were depressed. This suggests that most hypocretin cells probably express opioid receptors and are inhibited by opiates, but the amplitude of the effect on gene expression may not have been great enough in all cells to induce a change in CRE or c-fos expression in the previous study. Alternately, the short-lived CRE or c-fos responses might be evident in a great number of cells at times other than those previously tested. Given the consistent inhibitory responses to dynorphin, mENK, and morphine, and the block of those respective actions by selective antagonists, hypocretin neurons appear to express both $\mu$ - and $\kappa^{-}$, but probably not $\delta$-, opioid receptors.

Opioids may depress cognitive arousal by inhibiting neuronal systems that are targets of hypocretin axons, including the noradrenergic neurons of the locus ceruleus, the midline thalamic arousal system, and prefrontal cortex, and by attenuating hypocretin-mediated glutamate release (Lambe and Aghajanian, 2003). The present data suggest that opioids can also directly depress the hypocretin neurons, further underlining the high level of potential interaction between the proarousal hypocretin and the arousal-depressing opioids.

\section{Drugs of abuse, reward, and the hypocretin system}

One of the highest levels of electrical self stimulation is found when electrodes are implanted in the LH in the area where hypocretin neurons are located, and thus cells here may play a role in reward responses. Hypocretin neurons maintain axonal communication with several areas of the brain that have been implicated in drug addiction and reward, including the ventral tegmental area and nucleus accumbens (Peyron et al., 1998). Our data here show that in addition to the axonal projections to regions of the brain involved in reward and drug abuse, hypocretin neurons are directly inhibited by opiates, and that excitatory axons presynaptic to hypocretin neurons also are inhibited by both opiates and cannabinoids (Huang et al., 2007). Both sets of drugs are also considered to induce soporific responses in drug abusers and disrupt focused attention. By multiple presynaptic and postsynaptic mechanisms, opioids and cannabinoids depress the hypocretin arousal system. This suggests that the hypocretin cell may be one target whereby these drugs reduce awareness and enhance sleep probability, a central characteristic of continued use of narcotic drugs. Recent work has shown the importance of hypocretin receptors in drug dependence and withdrawal, that hypocretin modulates responses to other neurotransmitters involved in drug dependence, and that the absence of hypocretin reduced cocainemediated locomotor sensitization and morphine-mediated place dependence (Borgland et al., 2006; Narita et al., 2006). In addition to the importance of the modulation of hypocretin actions in target areas of the brain, the present study shows that opiates strongly inhibit the hypocretin cells by multiple direct and presynaptic actions, indicating that drugs of abuse may not only influence hypocretin target neurons, but also have a substantial effect directly on the hypocretin neurons. The finding here that hypocretin neurons appear to be under tonic inhibition by opioid 
receptor activation raises an interesting question of whether some of the effects of exposure to opiates on cognitive arousal may be caused by a shift in the sensitivity of the hypocretin neurons to the local inhibitory effect of endogenous opioid peptides.

\section{References}

Borgland SL, Taha SA, Sarti F, Fields HL, Bonci A (2006) Orexin A in the VTA is critical for the induction of synaptic plasticity and behavioral sensitization to cocaine. Neuron 49:589-601.

Cazala P, Darracq C, Saint-Marc M (1987) Self-administration of morphine into the lateral hypothalamus in the mouse. Brain Res 416:283-288.

Desjardins GC, Brawer JR, Beaudet A (1990) Distribution of mu, delta, and kappa opioid receptors in the hypothalamus of the rat. Brain Res 536:114-123.

Fallon JH, Leslie FM (1986) Distribution of dynorphin and enkephalin peptides in the rat brain. J Comp Neurol 249:293-336.

Gao XB, van den Pol AN (1999) NT-3 potentiates excitatory GABAergic synaptic transmission in cultured developing hypothalamic neurons of the rat. J Physiol (Lond) 518:81-95.

Georgescu D, Zachariou V, Barrot M, Mieda M, Willie JT, Eisch AJ, Yanagisawa M, Nestler EJ, DiLeone RJ (2003) Involvement of the lateral hypothalamic peptide orexin in morphine dependence and withdrawal. J Neurosci 23:3106-3111.

Harris GC, Wimmer M, Jones GA (2005) A role for lateral hypothalamic orexin neurons in reward seeking. Nature 437:556-559.

Huang H, Acuna-Goycolea C, Li Y, Cheng HM, Obrietan K, van den Pol AN (2007) Cannabinoids excite hypothalamic melanin-concentrating hormone but inhibit hypocretin/orexin neurons: implications for cannabinoid actions on food intake and cognitive arousal. J Neurosci 27:4870-4881.

Lambe EK, Aghajanian GK (2003) Hypocretin (orexin) induces calcium transients in single spines postsynaptic to identified thalamocortical boutons in prefrontal slice. Neuron 40:139-150.

Lane-Ladd SB, Pineda J, Boundy VA, Pfeuffer T, Krupinski J, Aghajanian GK, Nestler EJ (1997) CREB (cAMP response element-binding protein) in the locus coeruleus: biochemical, physiological, and behavioral evidence for a role in opiate dependence. J Neurosci 17:7890-7901.

Lestang I, Cardo B, Roy MT, Velley L (1985) Electrical self-stimulation deficits in the anterior and posterior parts of the medial forebrain bundle after ibotenic acid lesion of the middle lateral hypothalamus. Neuroscience 15:379-388.
Li Y, van den Pol AN (2006) Differential target dependent actions of coexpressed inhibitory dynorphin and excitatory hypocretin/orexin neuropeptides. J Neurosci 26:13037-13047.

Li Y, Gao XB, Sakurai T, van den Pol AN (2002) Hypocretin/orexin excites hypocretin neurons via a local glutamate neuron - a potential mechanism for orchestrating the hypothalamic arousal system. Neuron 36:1169-1181.

Mansour A, Khachaturian H, Lewis ME, Akil H, Watson SJ (1988) Anatomy of CNS opioid receptors. Trends Neurosci 11:308-314.

Narita M, Nagumo Y, Hashimoto S, Narita M, Khotib J, Miyatake M, Sakurai T, Yanagisawa M, Nakamachi T, Shioda S, Suzuki T (2006) Direct involvement of orexinergic systems in the activation of the mesolimbic dopamine pathway and related behaviors induced by morphine. J Neurosci 26:398-405.

Nassif S, Cardo B, Libersat F, Velley L (1985) Comparison of deficits in electrical self-stimulation after ibotenic acid lesion of the lateral hypothalamus and the medial prefrontal cortex. Brain Res 332:247-257.

Nestler EJ, Aghajanian GK (1997) Molecular and cellular basis of addiction. Science 278:58-63.

Pan YX, Xu J, Bolan E, Moskowitz HS, Xu M, Pasternak GW (2005) Identification of four novel exon 5 splice variants of the mouse mu-opioid receptor gene: functional consequences of C-terminal splicing. Mol Pharmacol 68:866-875.

Peyron C, Tighe DK, van den Pol AN, de Lecea L, Heller HC, Sutcliffe JG, Kilduff TS (1998) Neurons containing hypocretin (orexin) project to multiple neuronal systems. J Neurosci 18:9996-10015.

Peyron C, Faraco J, Rogers W, Ripley B, Overeem S, Charnay Y, Nevsimalova S, Aldrich M, Reynolds D, Albin R, Li R, Hungs M, Pedrazzoli M, Padigaru M, Kucherlapati M, Fan J, Maki R, Lammers GJ, Bouras C, Kucherlapati R, et al. (2000) A mutation in a case of early onset narcolepsy and a generalized absence of hypocretin peptides in human narcoleptic brains. Nat Med 6:991-997.

Thannickal TC, Moore RY, Nienhuis R, Ramanathan L, Gulyani S, Aldrich M, Cornford M, Siegel JM (2000) Reduced number of hypocretin neurons in human narcolepsy. Neuron 27:469-474.

Wise RA (2002) Brain reward circuitry: insights from unsensed incentives. Neuron 36:229-240.

Zhou Y, Bendor J, Hofmann L, Randesi M, Ho A, Kreek MJ (2006) Mu opioid receptor and orexin/hypocretin mRNA levels in the lateral hypothalamus and striatum are enhanced by morphine withdrawal. J Endocrinol 191:137-145. 